\title{
Addressing the Social Determinants of Health in Undergraduate Medical Education Curricula: A Survey Report
}

This article was published in the following Dove Press journal:

Advances in Medical Education and Practice

\author{
Joy H Lewis' \\ Onelia G Lage ${ }^{2}$ \\ B Kay Grant ${ }^{3}$ \\ Senthil K Rajasekaran ${ }^{4}$ \\ Mekbib Gemeda (iD ${ }^{5}$ \\ Robert C Like (iD) \\ Sally Santen ${ }^{7}$ \\ Michael Dekhtyar (10) ${ }^{8}$ \\ 'School of Osteopathic Medicine in \\ Arizona, A.T. Still University of Health \\ Sciences, Mesa, AZ, USA; ${ }^{2}$ Herbert \\ Wertheim College of Medicine, Florida \\ International University, Miami, FL, USA; \\ ${ }^{3}$ Office of Health Professions Education, \\ Nebraska Medicine, Omaha, NE, USA; \\ ${ }^{4}$ Academic Affairs, Eastern Virginia \\ Medical School, Norfolk, VA, USA; \\ ${ }^{5}$ Diversity and Inclusion, Eastern Virginia \\ Medical School, Norfolk, VA, USA; \\ ${ }^{6}$ Department of Family Medicine and \\ Community Health, Robert Wood \\ Johnson Medical School, Rutgers \\ University, New Brunswick, NJ, USA; \\ ${ }^{7}$ Department of Emergency Medicine, \\ Virginia Commonwealth University, \\ Richmond, VA, USA; ${ }^{8}$ Medical Education \\ Outcomes, American Medical \\ Association, Chicago, IL, USA
}

Purpose: Social determinants of health $(\mathrm{SDH})$ are recognized as important factors that affect health and well-being. Medical schools are encouraged to incorporate the teaching of $\mathrm{SDH}$. This study investigated the level of commitment to teaching SDH; learning objectives/ goals regarding student knowledge, skills, and attitudes; location in the curriculum and teaching strategies; and perceived barriers to teaching SDH.

Methods: A team from the American Medical Association's Accelerating Change in Medical Education Consortium developed a 23-item inventory survey to document consortium school SDH curricula. The 32 consortium schools were invited to participate.

Results: Twenty-nine (94\%) schools responded. Most respondents indicated the teaching of SDH was low priority $(10,34 \%)$ or high priority $(12,41 \%)$. Identified learning objectives/ goals for student knowledge, skills, and attitudes regarding SDH were related to the importance of students developing the ability to identify and address SDH and recognizing $\mathrm{SDH}$ as being within the scope of physician practice. Curricular timing and teaching strategies suggested more SDH education opportunities were offered in the first and second undergraduate medical education years. Barriers to integrating SDH in curricula were identified: addressing SDH is outside the realm of physician responsibility, space in curriculum is limited, faculty lack knowledge and skills to teach material, and concepts are not adequately represented on certifying examinations.

Conclusion: Despite the influence of SDH on individual and population health, programs do not routinely prioritize SDH education on par with basic or clinical sciences. The multitude of learning objectives and goals related to SDH can be achieved by increasing the priority level of SDH and employing better teaching strategies in all years. The discordance between stated objectives/goals and perceived barriers, as well as identification of the variety of strategies utilized to teach SDH during traditional "preclinical" years, indicates curricular areas in need of attention.

Keywords: health system science, teaching strategies, social factors, barriers to teaching

\section{Introduction}

The combination of social and environmental factors has a greater impact than clinical care on health outcomes. ${ }^{1-4}$ In 2005, the United Nations convened the Commission on Social Determinants of Health, which called for the re-orientation of health systems to focus on health promotion and population health. ${ }^{5}$ Social determinants of health (SDH) are defined by the World Health Organization as "the conditions in which people are born, grow, work, live, age, and the wider set of
Correspondence: Joy H Lewis School of Osteopathic Medicine in Arizona, A.T. Still University of Health Sciences, 5850 E Still Circle, Mesa AZ 85026 USA

Tel +I 307-200-7009

$\mathrm{Fax}+\mid$ 480-219-6110

Email jhlewis@atsu.edu 
forces and systems shaping the conditions of daily life." Given the complex interactions between social conditions, health, and well-being, the American College of Physicians, the National Academy of Sciences, the Department of Health and Human Services, and others recommend health professionals be taught to consider patients' unique risk factors in order to identify effective interventions in the context of each person's socioeconomic status, social environment, and physical environment. ${ }^{7-11}$ Medicine has made progress by elucidating the molecules, genes, and biological systems that are implicated in diseases; however, health disparities persist, in part, because social factors have not been adequately considered as part of holistic or whole-patient care. ${ }^{12,13}$ Undergraduate medical education (UME) training related to SDH is an important upstream approach to equip future physicians with the knowledge, skills, and attitudes needed to address disparities and foster health equity. ${ }^{14-16}$

Medical education related to SDH is important for future providers who will enter a changing health-care environment. Given the increasing interest in meeting the Quadruple Aim and the push for value-based care, ongoing health system reform is taking place and includes the growth of patient-centered medical homes, accountable care organizations, and integrated delivery systems. ${ }^{17}$ Along with improving health outcomes for individual patients, there is a focus on improving population and community health. For success, these initiatives require health-care providers and health systems to pay particular attention to $\mathrm{SDH} .{ }^{18,19}$

The American Medical Association's Accelerating Change in Medical Education (ACE) Consortium consists of 32 medical schools who work together to transform physician training to prepare the providers of the future. ${ }^{20}$ The study of SDH is an integral component within the population health domain of the newly actualized Health Systems Science (HSS) curricula developed by the consortium. ${ }^{21}$ By combining knowledge of basic, clinical, and HSS curricula, health professionals should be better prepared to improve the health of individuals and populations. Individual medical schools with social missions have developed training opportunities to improve SDH education. ${ }^{22,23}$ For example, longitudinal servicelearning experiences that address SDH through householdcentered care for underserved communities can increase medical student experience in addressing health disparities. $^{24}$ While there are many schools providing directed SDH education, there has been limited SDH curricular dissemination. ${ }^{25}$ Various programs have published aspects of their curriculum; however, the extent of SDH-related training in medical schools remains unknown. ${ }^{25-27}$ Therefore, a multi-institutional study of consortium schools was conducted to determine the level of commitment to teaching about SDH; learning objectives/goals regarding student knowledge, skills, and attitudes related to SDH; location in the curriculum and teaching strategies for $\mathrm{SDH}$; and perceived barriers to teaching SDH in the ACE schools.

\section{Materials and Methods Data Collection}

In March 2016, the authors formed an interest group focused on SDH within the ACE consortium to increase collaboration and share materials and experiences regarding teaching SDH. This group, all of whom had expertise in teaching SDH and implementing initiatives to promote health equity, developed a 23-item electronic survey through an iterative consensus-building process. The team outlined domains for the survey and discussed them at group meetings. Specific survey items were initially written by 2 team members, and 6 team members tested each item. Each team member provided feedback to the lead survey writers regarding their interpretation of and evaluation of each survey item. The lead survey writers then edited the survey, and all authors reviewed and discussed each draft. Each member of the project team evaluated every survey item, and group discussions were used to ensure consistent interpretation and to improve content and response process validity. The survey addressed the 4 study objectives. The survey is available in the Appendix.

To determine the level of institutional commitment to teaching about $\mathrm{SDH}$, we asked respondents to rate the level at which methods to explicitly teach about SDH are prioritized in the overall curriculum at their institution. Response options were as follows: extremely low priority, SDH are not explicitly or purposefully mentioned in the curriculum; low priority, SDH are mentioned but are not a focus; high priority, SDH receive attention at multiple levels; or extremely high priority, SDH receive as much attention as a basic science course (anatomy, physiology) or a clinical course (cardiology).

Information about learning objectives/goals regarding student knowledge, skills, and attitudes related to SDH was obtained through open-ended questions that provided 
qualitative data. Location in the curriculum and teaching strategies for SDH were evaluated by asking respondents to identify the level at which teaching about $\mathrm{SDH}$ is integrated into the curriculum at their institution. The response options included: not offered at all; offered in one course, module, or clerkship; offered in more than one course, module, or clerkship, but not a theme across courses, modules, or clerkships; a theme across the curriculum and tied in with mission of school; or will be offered in the near future.

Additionally, information about teaching strategies was obtained using pre-identified options. The study team utilized their expertise and available literature to construct a comprehensive list of potential methods used to teach about SDH. Respondents were asked to identify methods used at their institution to explicitly teach about SDH and to identify the UME years where the methods were utilized. Respondents could select all methods that applied and had space to provide details about additional strategies not listed.

Perceived barriers to teaching SDH were identified by asking respondents to rate potential barriers from a list. Potential barriers were ranked on a scale from 1 to 3 , where 1 was defined as not a barrier and 3 was defined as a significant barrier. The team used previously reported barriers and experiences of ACE consortium schools to develop options for potential barriers to integrating $\mathrm{SDH}$ elements into the UME curriculum. ${ }^{28}$ Open-ended responses were obtained for the item, "Please describe and briefly explain the biggest barriers to explicitly teaching the social determinants."

The study was considered exempt by the appropriate institutional review board because it was part of the consortium's overall research and program evaluation protocol. In March 2017, the survey was sent by e-mail to leaders from the 32 schools in the ACE consortium. These leaders were all active members of the ACE consortium. As active consortium members, each respondent was someone with intimate knowledge of the curriculum at their institution. They were asked to complete the survey or to share it with a faculty member or administrator who would have substantial, detailed knowledge about their curriculum and SDH. One new school was subsequently excluded since they had only a single cohort of students at the time of data collection.

\section{Analysis}

Survey responses related to perceived level of commitment were quantified. Learning objectives/goals regarding student knowledge, skills, and attitudes related to SDH were categorized based on the objectives for knowledge and skills that faculty would like students to possess upon graduation. Goals related to the attitudes faculty would like to see students exhibit were summarized. One investigator initially reviewed all open-ended responses and categorized them as knowledge, skills, or attitudes. The responses were then combined into similar topic sentences and were edited to provide an overview of the breadth of objectives. All investigators came to a consensus on the categorizations and worked together through electronic interactions and regular phone conversations to combine responses into succinct messages.

Location in the curriculum and teaching strategies for SDH were evaluated by summarizing the reported types of and curricular offerings and location in the UME curriculum when experiences were provided. We calculated frequency and proportion of responses for categorical questions assessing the types and location in the curriculum. Additionally, we compared differences in the location of curricular offerings between the four academic years using the chi-squared test. SAS software version 9.4 (Cary, NC) and Microsoft Excel were used for analyses.

Ratings for perceived barriers that prevent institutions from prioritizing SDH in the curriculum or prevent faculty from teaching about SDH were summarized. For the openended question about the biggest perceived barriers to prioritizing SDH in the curriculum, we categorized responses into themes and created summary statements. All investigators reviewed the categorizations and summary statements and agreed on the qualitative results.

\section{Results}

Leaders from 29 of the 31 (94\%) schools responded to the survey.

\section{Level of Commitment to Teaching SDH}

Of the 29 respondents, 28 answered the question asking them to rate the level at which methods to explicitly teach about SDH were prioritized in the overall curriculum at their institution. Most respondents indicated low priority $(10,34 \%)$ or high priority $(12,41 \%)$ (Figure 1$)$.

\section{Learning Objectives/Goals Related to $\mathrm{SDH}$}

A qualitative analysis with categorized and summarized responses related to objectives for imparting knowledge and skills and to goals regarding student attitudes on 


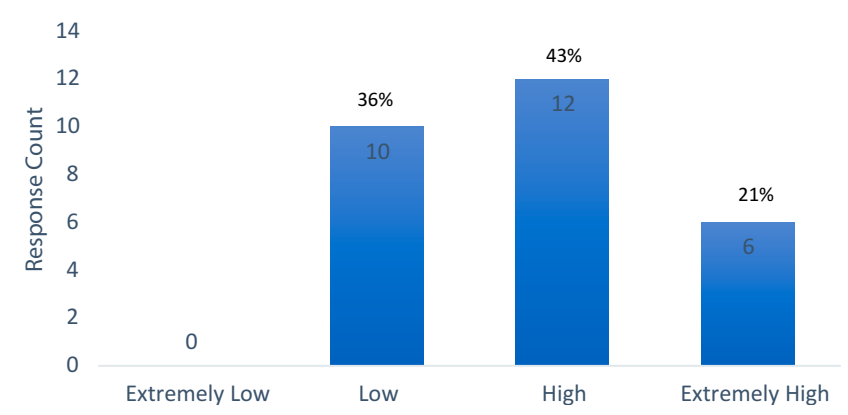

Figure I Level of priority given to social determinants of health $(\mathrm{SDH})$ in the curriculum $(\mathrm{N}=28)$.

completion of their UME programs is presented in Table 1. Identified objectives for students included the ability to define SDH and describe how SDH influence health and disease for patients and populations. Respondents also detailed learning objectives for skills such as the ability to conduct and document a full SDH history and to address SDH with respect and cultural sensitivity. These qualitative results delineate the breadth of responses that include the ability to describe systems of health care and the skill of applying principles of high-value care. Goals related to student attitudes included the appreciation that identifying and addressing SDH are important roles for physicians and that physicians are advocates for patients and populations.

\section{Location in the Curriculum and Teaching Strategies for SDH}

Each respondent described where the teaching of SDH takes place in their curriculum (Figure 2). For half the schools $(14,50 \%), \mathrm{SDH}$ education was provided in more than one course, module, or clerkship but was not a theme across courses, modules, or clerkships. For a quarter of schools $(7,25 \%)$, SDH were an overall theme across the curriculum and were tied in with the mission of the school.

Types of teaching strategies and the UME year of training where each was offered is presented in (Table 2). The number of responses to SDH teaching strategies offered decreased from the first year of UME through the fourth year, eg, "case studies with specific SDH elements included" as a strategy was said to be offered in the first year by $79 \%$ of the respondents and the corresponding proportion for the second year, third year and fourth year were approximately $62 \%, 34 \%$ and $7 \%$, respectively. A trend test (chisquared) showed a significant decrease from first-to-fourth years $(p<0.001)$. Bonferroni-corrected pairwise tests showed significant decreases from the first to both the third and fourth years $(p<0.05)$, and a decrease from the second year to the
Table I Identified Learning Objectives for Knowledge and Skills and Goals Related to Attitudes for Students Regarding Social Determinants of Health (SDH)

\begin{tabular}{|l|}
\hline Learning Objectives \\
\hline Knowledge \\
\hline Define SDH and describe how SDH influence health and disease for \\
patients and populations \\
Describe systems of health care \\
Define advocacy and discuss ways medical students can be involved in \\
advocacy \\
Explain how to address SDH using institutional and community resources \\
Explain the difference between health disparities and health-care \\
disparities
\end{tabular}

Skills

Conduct and document a full SDH history in the electronic health record

Address SDH with respect and cultural sensitivity utilizing appropriate resources

Apply principles of high value care while preserving quality

Demonstrate ability to assist patients with health system complexities

Assess health status of populations using available public health and surveillance data, apply and interpret statistical tests

Recommend appropriate preventive care for at-risk people and populations

Goals Related to Attitudes Regarding SDH

Understand the physician is a member of the care team, not always the leader

Appreciate that identifying and addressing SDH are important roles for physicians

Understand that it is important to identify health disparities and work to alleviate them

Understand the physician is an advocate for patients and populations

fourth year $(\mathrm{p}<0.05)$. Several respondents provided additional teaching strategies not included in the survey, such as a poverty simulation program in year 1 , servicelearning experiences in the community in years $1-3$, interprofessional student and faculty home visits in years $2-4$, individual work with a social worker, utilization of a health leads questionnaire to identify social factors patients were having difficulty with, personal narratives/reflections related to health disparities, and small group discussions (years not specified).

\section{Perceived Barriers to Teaching SDH}

Ratings for perceived barriers that prevented institutions and educators from teaching about SDH are presented in (Table 3). Likert scale responses were allowed from 1 to 3. 


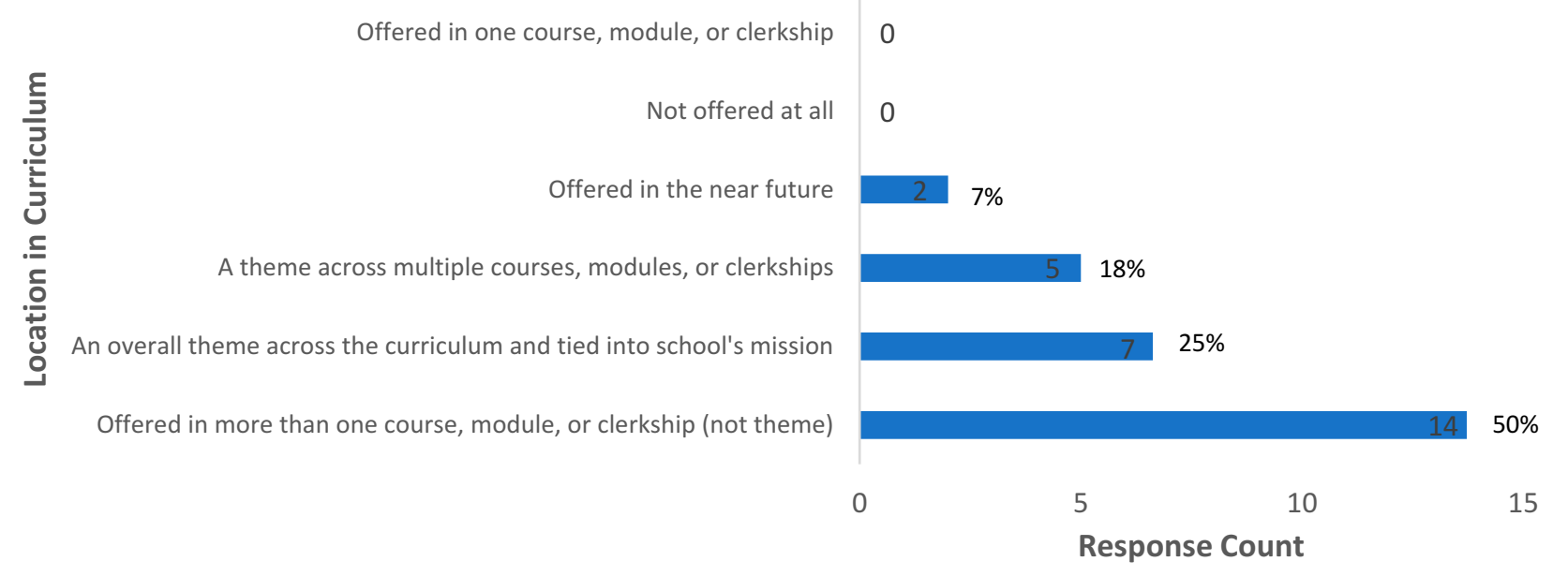

Figure 2 Location of social determinants of health $(\mathrm{SDH})$ in the curriculum $(\mathrm{N}=28)$.

A response of 1 indicated "not a barrier" and 3 indicated "a significant barrier." Items that were rated 2 or 3 by at least half of respondents as barriers to the institution prioritizing the teaching of SDH included general resistance to curricular change, not enough space in the curriculum, faculty lack of knowledge and skills regarding SDH, and SDH content not relevant to licensing exams. Items rated as 2 or 3 by at least half of respondents for barriers that can prevent faculty from teaching about SDH included: lack of dedicated time for teaching SDH, lack of expertise in SDH curricular development, lack of expertise in assessment, lack of identified experiential learning opportunities, and lack of faculty development opportunities.

Qualitative responses identifying the biggest perceived barriers to prioritizing SDH were characterized into 4 themes. First, SDH were perceived to be outside the realm of physician responsibility. Second, space in the medical school curriculum was limited. Third, faculty lacked the knowledge and skills to teach this material. Fourth, SDH was not practical content for students studying for board examinations given the lack of SDH concepts on United States Medical Licensing Examination (USMLE) certifying examinations.

\section{Discussion}

Results of the current study suggested medical schools are successfully integrating SDH-related content into UME curricula. To the best of our knowledge, the current study is the first to survey multiple US academic medical institutions to assess the current state of their SDH curricula.

While there is substantial research demonstrating the considerable contribution of SDH to mortality and

Table 2 Identified Teaching Strategies and Curricular Timing for Social Determinants of Health

\begin{tabular}{|c|c|c|c|c|}
\hline \multirow[t]{2}{*}{ Teaching Strategies } & \multicolumn{4}{|c|}{ Survey Responses $(\mathbf{N}=29)$} \\
\hline & First Year & Second Year & Third Year & Fourth Year \\
\hline Case studies with specific SDH elements included & $23(79 \%)$ & $18(62 \%)$ & $10(34 \%)$ & $2(7 \%)$ \\
\hline Virtual patient panels with SDH of health elements included & $6(21 \%)$ & $6(21 \%)$ & $2(7 \%)$ & $0(0 \%)$ \\
\hline Teaching electronic health record with SDH conditions listed & $4(14 \%)$ & $7(24 \%)$ & $5(17 \%)$ & $2(7 \%)$ \\
\hline Community-based service programs or research projects & $18(62 \%)$ & $12(4 \mid \%)$ & II (38\%) & $9(31 \%)$ \\
\hline Requirement to conduct needs assessment(s) looking at SDH & $9(31 \%)$ & $5(17 \%)$ & $5(17 \%)$ & $\mathrm{I}(3 \%)$ \\
\hline History-taking tool that addresses SDH & $18(62 \%)$ & $17(59 \%)$ & 15 (52\%) & $6(21 \%)$ \\
\hline $\begin{array}{l}\text { Integrated interprofessional experiences during which students learn with and } \\
\text { from peers or professionals in other health care professions }\end{array}$ & $17(59 \%)$ & $16(55 \%)$ & $13(45 \%)$ & $7(24 \%)$ \\
\hline $\begin{array}{l}\text { Having visiting guests/advocates from community-based organizations involved in } \\
\text { addressing SDH }\end{array}$ & $19(66 \%)$ & $15(52 \%)$ & $7(24 \%)$ & $3(10 \%)$ \\
\hline Readings and films about addressing SDH & $19(66 \%)$ & $13(45 \%)$ & 7 (24\%) & $3(10 \%)$ \\
\hline
\end{tabular}

Notes: Data are reported as frequency (\%). 
Table 3 Ratings for Potential Barriers That Prevent Institutions from Prioritizing Social Determinants of Health (SDH) in the Curriculum or Prevent Faculty from Teaching About SDH

\begin{tabular}{|c|c|c|c|}
\hline \multirow[t]{2}{*}{ Potential Barriers } & \multicolumn{3}{|c|}{ Survey Responses $(\mathbf{N}=\mathbf{2 8})$} \\
\hline & I & 2 & 3 \\
\hline \multicolumn{4}{|l|}{ Perceived Barriers to Prioritizing SDH } \\
\hline $\begin{array}{l}\text { General resistance to curricular change } \\
\text { Not enough space for new content in the curriculum } \\
\text { Faculty lack knowledge and skills regarding } \mathrm{SDH}^{\mathrm{a}} \\
\text { Experiential roles for students do not exist to effectively learn this material } \\
\text { Faculty perceptions are that students are not prepared to learn this material } \\
\text { Support from administration and leadership } \\
\text { SDH content not relevant to licensing exams }\end{array}$ & $\begin{array}{l}14(50 \%) \\
5(18 \%) \\
13(46 \%) \\
14(50 \%) \\
24(86 \%) \\
20(71 \%) \\
10(36 \%)\end{array}$ & $\begin{array}{l}12(43 \%) \\
10(36 \%) \\
7(25 \%) \\
11(39 \%) \\
3(11 \%) \\
7(25 \%) \\
12(43 \%)\end{array}$ & $\begin{array}{l}2(7 \%) \\
13(46 \%) \\
7(25 \%) \\
3(11 \%) \\
\text { I (3\%) } \\
\text { I (3\%) } \\
6(21 \%)\end{array}$ \\
\hline \multicolumn{4}{|l|}{ Perceived Barriers That Prevent Faculty from Teaching SDH } \\
\hline $\begin{array}{l}\text { Lack of dedicated time for teaching SDH } \\
\text { Lack of expertise in SDH curricular development } \\
\text { Lack of curricular materials } \\
\text { Lack of expertise in assessment } \\
\text { Lack of identified experiential learning opportunities } \\
\text { Lack of faculty development opportunities } \\
\text { Lack of support from administration for identifying issues outside the clinic }\end{array}$ & $\begin{array}{l}10(36 \%) \\
12(43 \%) \\
14(50 \%) \\
11(32 \%) \\
14(50 \%) \\
10(36 \%) \\
17(61 \%)\end{array}$ & $\begin{array}{l}9(32 \%) \\
12(43 \%) \\
12(43 \%) \\
12(43 \%) \\
9(32 \%) \\
12(43 \%) \\
9(32 \%)\end{array}$ & $\begin{array}{l}9(32 \%) \\
4(14 \%) \\
2(7 \%) \\
5(18 \%) \\
5(18 \%) \\
6(21 \%) \\
2(7 \%)\end{array}$ \\
\hline
\end{tabular}

Notes: Survey responses were based on a 3-point scale, where I was defined as not a barrier and 3 was defined as a significant barrier. ${ }^{\mathrm{a}} \mathrm{N}=\mathbf{2 7}$ for this item.

Abbreviations: ACE, The American Medical Association's Accelerating Change in Medical Education; SDH, social determinants of health; UME, undergraduate medical education.

morbidity when compared with clinical factors, ${ }^{1-4,29}$ only 6 respondents rated the level of priority given to SDH in their curriculum as extremely high, receiving as much attention as a basic or clinical science course. An additional 12 program leaders rated the level of priority as high, but the prioritization of SDH does not appear to accord with the degree to which SDH affect health and well-being. Medical education continues to emphasize biomedical content with less attention given to the socioecological context in which patients live. ${ }^{30}$ Instead, medical education should focus on the inclusion of social contexts of health in the training of health-care professionals to ensure students emerge from training prepared to serve the needs of diverse populations..$^{30,31}$ Trainees require specific knowledge and skills to achieve this. We encourage medical educators and accrediting boards to increase the emphasis placed on these concepts.

Survey respondents identified learning objectives for knowledge and skills and goals related to attitudes for students regarding SDH. The reported objectives included a high level of proficiency in identifying and addressing $\mathrm{SDH}$. Skills to be developed included applying principles of high value care while preserving quality and demonstrating the ability to assist patients with health system complexities. Attitudes included the appreciation that identifying and addressing SDH are important roles for physicians, who are not always the team leaders but are members of care teams. The depth and breadth of the identified objectives and attitudes demonstrated the need for integration of SDH education at all levels of UME. These objectives cannot be realized with lecture-based education alone, where content is isolated to specific courses. Unless preceptors and other physicians model the behavior of addressing $\mathrm{SDH}$, trainees will not develop the appreciation that these areas are within the realm of what physicians should address in clinical practice. Identifying these objectives is one step; fitting them into the curriculum is the next.

Survey responses indicated there were variations in the location of SDH in the curriculum and the teaching strategies used. For the question about the location of SDH, half of the respondents reported SDH elements were offered in more than one course module or clerkship but SDH were not a theme across courses, modules, or clerkships. As with clinical sciences, HSS with a focus on SDH should be longitudinally incorporated into UME. A longitudinal focus would provide a variety of experiences and contexts for students to identify and address $\mathrm{SDH}$. This focus is important because SDH are complex 
and affect all aspects of health and well-being. Education related to $\mathrm{SDH}$ can be integrated into routine longitudinal clinical and service-learning opportunities. With added emphasis and attention, future providers can be taught to explore and address SDH during all patient encounters.

The current study found there were markedly more teaching strategies for the first and second years of UME than for the third and fourth years. Although a multitude of strategies were identified and used, the relative focus on what are typically "preclinical" years of UME is a concern. For students to believe that identifying and addressing SDH are important roles for physicians, they need to see this modelled in clinical care. Further, to acquire the knowledge and skills necessary to address complex SDH for individuals and populations, students need experience doing so during clinical training. Integrated interprofessional experiences during which students learn with and from peers or professionals in other health-care professions was one of the most frequently identified strategies for all years of training. This strategy can be adopted by medical educators as a method to promote SDH clinical training. Although physician role models are important, interprofessional programs as required elements of UME clinical training can be beneficial. By working with colleagues and students in social work, case management, patient financial services, pharmacy, medicallegal organizations, and other areas, students and providers can learn how to identify and address important social factors that impact health and well-being. ${ }^{32}$ Medical schools facing barriers regarding curricular time and faculty development may wish to look to colleagues in other professions to pursue interprofessional opportunities.

Survey respondents identified perceived barriers to incorporating the teaching of SDH in UME that were similar to those identified for incorporating HSS more broadly. ${ }^{28}$ Faculty development is needed to encourage faculty to prioritize SDH as equally important aspects of medical education that need to be integrated with the biomedical content. One of the themes identified as an important barrier was the perception that SDH are outside the realm of physician responsibility. This perception is in direct contrast to our results for the goals regarding attitudes to foster. Therefore, physician educators should make a concerted effort to address this barrier. A second barrier was related to space in the curriculum. Because space is tied to prioritization, creating space in the curriculum can be accomplished if other, lower priority, elements are dropped. A third barrier was the perception that faculty lack the knowledge and skills required to teach this material. However, centralized, shared resources for faculty development and student education are increasingly important and available from various resources. ${ }^{14,33,34}$ Finally, SDH concepts were identified as being impractical for UME since content about it is lacking on the USMLE certifying examinations. As more medical educators focus on SDH in UME, the areas included in the evaluation can change, which is promising for addressing this barrier. Fortunately, there are already opportunities for students to explore SDH as part of HSS in a dedicated HSS examination. ${ }^{35}$

Perhaps lack of understanding of the broader context of SDH and how they relate to health and well-being for individuals and populations underscore the lack of prioritization in UME curricula. The persistence of disparities and inequities in health arises from the failure to understand and address the systemic nature of social factors and how they affect different communities in different ways. $^{29,36,37}$ Therefore, addressing SDH in UME can address the critical observations, most importantly from medical students, related to the underlying problems of an academic medical system walled in from the social reality of the community it wants to serve. ${ }^{38,39}$

The current study had several limitations. First, ACE schools represent a subset of all medical schools, so our results may not be generalizable to other schools. However, there are a wide variety of schools within the ACE consortium including top-ranked, research-focused, primary carefocused, public, private, and osteopathic programs. The current study showed variability in teaching SDH that is likely found across all schools. Another limitation is that the study relied on self-report by academic leaders from each program. We did not independently verify the curriculum offered by each consortium school. Since respondents were actively engaged with the consortium and curricular knowledge is an expectation of consortium members, it is unlikely that there were marked misrepresentations. Further, the survey identified curricular offerings but did not obtain details about how each program measures or plans to measure student competency in identifying or addressing SDH. Future work should include identifying and validating methods to measure competency in this area.

As the third pillar of UME, the promotion of HSS by the ACE consortium provides a context into which SDH education can be placed. HSS includes the domains of health-care structures and processes; health-care policy, economics, and management; clinical informatics and health information technology; population health; value-based care; and health system improvement. ${ }^{21}$ As these elements are introduced on 
equal footing with the basic and clinical sciences, SDH, which are critical elements of the population health domain of HSS, will receive more direct attention in UME curricula.

\section{Conclusion}

Social determinants of health are important elements affecting the health and well-being of individuals and populations. In the current study, medical educators identified learning objectives and goals related to SDH in UME. A multitude of teaching strategies and perceived barriers to providing SDH education were identified. The identified discrepancies between the objectives/goals and perceived barriers and the identification that more strategies were used to teach about SDH during the traditional "preclinical" years indicated curricular areas in need of critical attention. As a health professions education community, we should work to prioritize knowledge and skills related to SDH. We should model behavior by identifying and addressing SDH in clinical care and by advocating for patients and populations. This outcome can be accomplished as part of dynamic interprofessional health-care teams that recognize the importance of identifying health disparities and work to alleviate them. Further, we need to identify and address SDH as a major part of interconnected concepts within the emerging discipline of HSS. This is a call for dedicated action.

\section{Acknowledgments}

The authors would like to thank all the members of the consortium's social determinants of health interest group for their expertise in developing the survey instrument. The authors would also like to thank Debosree Roy, $\mathrm{PhD}$, for her help with preparation of the manuscript and Curt Bay, $\mathrm{PhD}$ for statistical analysis. The project was performed with financial support from the American Medical Association as part of the Accelerating Change in Medical Education Initiative.

\section{Disclosure}

Professor Barbara Kay Grant reports grants from the American Medical Association Change MedEd, outside the submitted work. The authors report no other conflicts of interest in this work.

\section{References}

1. Galea S, Tracy M, Hoggatt KJ, DiMaggio C, Karpati A. Estimated deaths attributable to social factors in the United States. Am J Public Health. 2011;101(8):1456-1465. doi:10.2105/AJPH.2010.300086
2. Jemal A, Thun MJ, Ward EE, Henley SJ, Cokkinides VE, Murray TE. Mortality from leading causes by education and race in the United States, 2001. Am J Prev Med. 2008;34(1):1-8. e7. doi:10.1016/j. amepre.2007.09.017

3. Schroeder SA. We can do better-improving the health of the American people. $N$ Engl J Med. 2007;357(12):1221-1228. doi:10. 1056/NEJMsa073350

4. Hood CM, Gennuso KP, Swain GR, Catlin BB. County health rankings: relationships between determinant factors and health outcomes. Am J Prev Med. 2016;50(2):129-135. doi:10.1016/j.amepre.2015.08.024

5. Baum F. The commission on the social determinants of health: reinventing health promotion for the twenty-first century? Crit Public Health. 2008;18(4):457-466. doi:10.1080/09581590802443612

6. WHO. Social determinants of health; 2019 Available from: https:// www.who.int/social_determinants/en/. Accessed September 9, 2019.

7. Link BG, Phelan J. Social conditions as fundamental causes of disease. J Health Soc Behav. 1995;35:80-94. doi:10.2307/2626958

8. Daniel H, Bornstein SS, Kane GC. Addressing social determinants to improve patient care and promote health equity: an American College of Physicians position paper. Ann Intern Med. 2018;168(8):577-578. doi:10.7326/M17-2441

9. U.S. Department of Health and Human Services. Healthy people 2020: an opportunity to address social determinants of health in the United States. Available from: https://www.healthypeople.gov/2010/hp2020/ advisory/SocietalDeterminantsHealth.htm.. Accessed September 9, 2019.

10. Beyond Flexner Alliance. Social mission in health professions education. Available from: http://beyondflexner.org/. Accessed September 20, 2019.

11. AAFP. The EverYONE project; advancing health equity in every community. Available from: https://www.aafp.org/patient-care/socialdeterminants-of-health/everyone-project.html. Accessed June 15, 2018.

12. Chokshi DA. Teaching about health disparities using a social determinants framework. J Gen Intern Med. 2010;25(2):182-185. doi:10.1007/s11606-009-1230-3

13. Marmot M, Friel S, Bell R, Houweling TA, Taylor S; Health CoSDo. Closing the gap in a generation: health equity through action on the social determinants of health. Lancet. 2008;372(9650):1661-1669. doi:10.1016/S0140-6736(08)61690-6

14. National Academies of Sciences Engineering, and Medicine. A Framework for Educating Health Professionals to Address the Social Determinants of Health. Washington, DC: The National Academies Press; 2016. doi:10.17226/21923

15. Mangold KA, Bartell TR, Doobay-Persaud AA, Adler MD, Sheehan KM. Expert consensus on inclusion of the social determinants of health in undergraduate medical education curricula. Acad Med. 2019;94(9):1355-1360. doi:10.1097/ACM.00000000000002593

16. Acosta D, Ackerman-Barger K. Breaking the silence: time to talk about race and racism. Acad Med. 2017;92(3):285-288. doi:10.1097/ ACM.0000000000001416

17. Bodenheimer T, Sinsky C. From triple to quadruple aim: care of the patient requires care of the provider. Ann Fam Med. 2014;12 (6):573-576. doi:10.1370/afm.1713

18. Alley DE, Asomugha CN, Conway PH, Sanghavi DM. Accountable health communities - addressing social needs through medicare and medicaid. N Engl J Med. 2016;374(1):8-11. doi:10.1056/NEJMp1512532

19. Gottlieb L, Colvin JD, Fleegler E, Hessler D, Garg A, Adler N. Evaluating the accountable health communities demonstration project. J Gen Intern Med. 2017;32(3):345-349. doi:10.1007/s11606-016-3920-y

20. AMA. AMA outlines ambitious approach toward health equity. Available from: https://www.ama-assn.org/ama-outlines-ambitiousapproach-toward-health-equity. Accessed October 5, 2018.

21. Skochelak SE, Hawkins RE, Lawson LE, Starr SR, Borkan J, Gonzalo JD. Health Systems Science E-Book. Elsevier Health Sciences; 2016. 
22. Mullan F. Social mission in health professions education: beyond flexner. JAMA. 2017;318(2):122-123. doi:10.1001/jama.2017.7286

23. Lewis JH, Whelihan K, Roy D. Teaching students to identify and document social determinants of health. Adv Med Educ Prac. 2019;2019(10):653-655. doi:10.2147/AMEP.S206819

24. Greer PJ Jr, Brown DR, Brewster LG, et al. Socially accountable medical education: an innovative approach at Florida International University Herbert Wertheim College of Medicine. Acad Med. 2018;93(1):60-65. doi:10.1097/ACM.0000000000001811

25. Doobay-Persaud A, Adler MD, Bartell TR, et al. Teaching the social determinants of health in undergraduate medical education: a scoping review. J Gen Intern Med. 2019;34(5):720-730. doi:10.1007/s11606019-04876-0

26. Muntinga M, Krajenbrink V, Peerdeman S, Croiset G, Verdonk P. Toward diversity-responsive medical education: taking an intersectionality-based approach to a curriculum evaluation. $A d v$ Health Sci Educ. 2016;21(3):541-559. doi:10.1007/s10459-0159650-9

27. Chrisman-Khawam L, Abdullah N, Dhoopar A. Teaching health-care trainees empathy and homelessness IQ through service learning, reflective practice, and altruistic attribution. Int J Psychiatry Med. 2017;52(3):245-254. doi:10.1177/0091217420913001

28. Gonzalo JD, Caverzagie KJ, Hawkins RE, Lawson L, Wolpaw DR, Chang A. Concerns and responses for integrating health systems science into medical education. Acad Med. 2018;93(6):843-849. doi:10.1097/ACM.0000000000001960

29. Braveman P, Gruskin S. Defining equity in health. J Epidemiol Community Health. 2003;57(4):254-258. doi:10.1136/jech.57.4.254
30. Vanselow N, Cuff PA. Improving Medical Education: Enhancing the Behavioral and Social Science Content of Medical School Curricula. National Academies Press; 2004.

31. Vidaeff AC, Kerrigan AJ, Monga M. Cross-cultural barriers to health care. South MedJ. 2015;108(1):1-4. doi:10.14423/SMJ.0000000000000221

32. Tobin Tyler E. Medical-legal partnership in primary care: moving upstream in the clinic. Am J Lifestyle Med. 2017;1559827617698417.

33. American Medical Association. Social determinants of health- AMA health systems science learning series; 2019. Availabe from: https:// edhub.ama-assn.org/health-systems-science/interactive/17498806. Accessed September 5, 2018.

34. Ehrenfeld JM, Gonzalo JD. Health Systems Science Review E-Book. Elsevier Health Sciences; 2019.

35. Dekhtyar M, Ross LP, D'Angelo J, et al. Validity of the health systems science examination: relationship between examinee performance and time of training. Am J Med Qual. 2020;35(1):63-69. doi:10.1177/1062860619853349

36. Freire P. Pedagogy of the oppressed. New York: Continuum, 2000. February. 1970;4:2014.

37. Jones CP. Levels of racism: a theoretic framework and a gardener's tale. Am J Public Health. 2000;90(8):1212.

38. Brooks KC. A silent curriculum. JAMA. 2015;313(19):1909-1910. doi:10.1001/jama.2015.1676

39. Lehmann LS, Sulmasy LS, Desai S. Hidden curricula, ethics, and professionalism: optimizing clinical learning environments in becoming and being a physician: a position paper of the American College of Physicians. Ann Intern Med. 2018;168(7):506-508. doi:10.7326/ M17-2058

\section{Publish your work in this journal}

Advances in Medical Education and Practice is an international, peerreviewed, open access journal that aims to present and publish research on Medical Education covering medical, dental, nursing and allied health care professional education. The journal covers undergraduate education, postgraduate training and continuing medical education including emerging trends and innovative models linking education, research, and health care services. The manuscript management system is completely online and includes a very quick and fair peer-review system. Visit http://www.dovepress.com/testimonials.php to read real quotes from published authors.

Submit your manuscript here: http://www.dovepress.com/advances-in-medical-education-and-practice-journal 